\title{
AXIAL BLAST DISCHARGE CHAMBER WITH MOVING ELECTRODE
}

\author{
M.E. PinchuK ${ }^{a, *}$, A.V. Budin ${ }^{a}$, N.K. KURAKInA ${ }^{a, b}$, A.G. LeKS ${ }^{a}$ \\ ${ }^{a}$ Institute for Electrophysics and Electric Power of Russian Academy of Sciences, Dvortsovaya nab., 18, \\ St.-Petersburg, 191186, Russia \\ ${ }^{b}$ Peter the Great Saint-Petersburg Polytechnic University, Polytechnicheskaya 29, St.-Petersburg 195251, Russia \\ * pinchme@mail.ru
}

\begin{abstract}
The paper presents some results concerning electrophysical and gas-dynamics parameters of high-curent arc in axial blast discharge chamber. The experimental stand and numerical model were modified for axial gas flow type. Some design changes are described in the paper. The experiments were carried out for gas pressures of 1.0-6.0 MPa with current amplitude of 25-150 kA. The current half-period was of 1.0-10.0 ms. The contacts moved apart to the distance of $3-4 \mathrm{~cm}$ due to gas pressure boost in the chamber. OpenFOAM package with the library swak4foam was used for numerical simulation.
\end{abstract}

Keywords: high-current high-pressure arc, high-current circuit breaker.

\section{Introduction}

Existing systems of energy generation and distribution face necessity of breaking current from tens up to several hundreds kiloampers $[1,2]$. The process of load switch-off is accompanied by an electric arc burning in all powerful switching off electric devices [3]. Now $\mathrm{SF}_{6}$ is the basic electrical insulation and arc-interruption media in powerful high-voltage and generator circuit breakers [4]. But $\mathrm{SF}_{6}$ is a potent greenhouse gas [4]. And general world position on the reduction of $\mathrm{SF}_{6}$ gas usage [4-6] demands development of new approaches in electric-power industry, namely, a wide search of new arc-interruption environments, and also new insulation and electrode materials suitable to work in these environments at high current amplitudes.

Besides needs of the electric power industry, research of powerful arc of variable length and methods of its quenching has the great importance for the development of various technologies of lightning protection [7-9], plasma chemistry [10, 11], aerodynamics $[12,13]$ and others. The carrying out of experimental researches of the high current discharges at high pressure requires the creation of complicated testing systems [14].

Earlier in our laboratory, the stand for research of lightning protection systems [15] and the stand for studying arc and erosive processes in high-current gas blast breakers $[16,17]$ had been built. In the development of researches [16-19] for this theme it was carried out the modernization of the systems. And it was designed a new axial blast discharge chamber. Additionally, with the development of experimental techniques the numerical model $[20,21]$ was developed for calculations of various processes in the given system. A brief description of the axial blast chamber and preliminary results are presented in the paper.

\section{Electrical power system and stand modernization}

The energy source of set-up is the modular capacitive system with maximal storage energy of $6 \mathrm{MJ}$, maximal charging voltage of $10 \mathrm{kV}$ and capacity of $0.11 \mathrm{~F}$. The capacitive system is divided into six identical independent modules which can be connect to loading as simultaneously, and with a delay. For the formation of an oscillation circuit the inductive reactors of 1.5, 50 and $250 \mu \mathrm{H}$, reeled up on textolite drums by PIGR-16 wire (produced by GK Sevkabel, St.Petersburg, Russia) are used. The discharge current is measured by Rogovsky coil. The voltage drop across an arc was measured using a high-ohmic resistive divider with transformer decoupling. For registration of pulse pressure in the discharge chamber the piezoelectric gauge of membrane type T500 or T200 (NTIIM, Nizhny Tagil, Russia) were used.

The duration of the current period in the contour was changed by choosing a number of charged modules and appropriate inductive reactor. Current curves for two modules and the specified inductive reactors are shown in figure 1.

The experimental stand was modified for axial blast discharge chamber. Air or nitrogen were used as working gas. The design of the discharge chamber is presented in figure 2 .

The housing of chamber (1) is a thick-walled vessel made from the stainless steel, inside it there is a mobile acetal resin piston (2). On the piston it is mounted the contact holder (3) on which end the contact tip (4) is screwed. The opposite end of the holder incorporates with the ground conductor line by means of flexible copper wires laid inside of polycarbonate tube (5). The ring-shaped contact (6) is fasten on the current input (7), isolated from the chamber case and connected with the high voltage conductor line. 


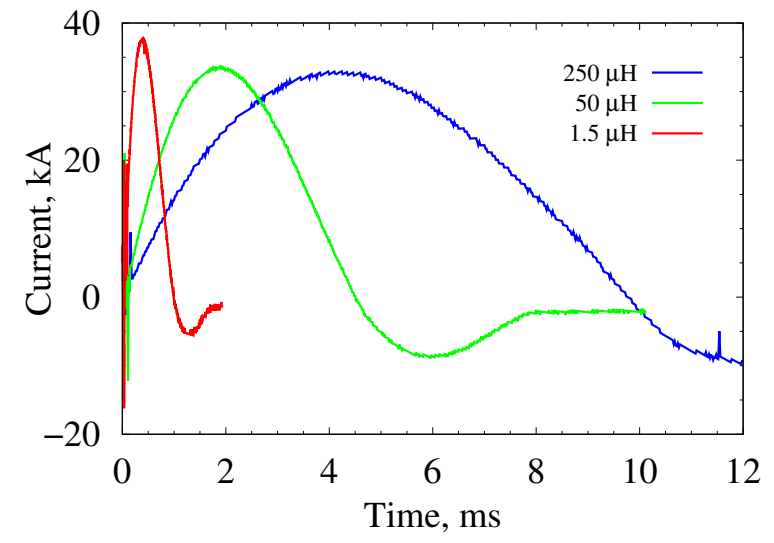

Figure 1. Short circuit current for capacity of $38 \mathrm{mF}$ and inductance of 1.5, 50 and $250 \mu \mathrm{H}$.

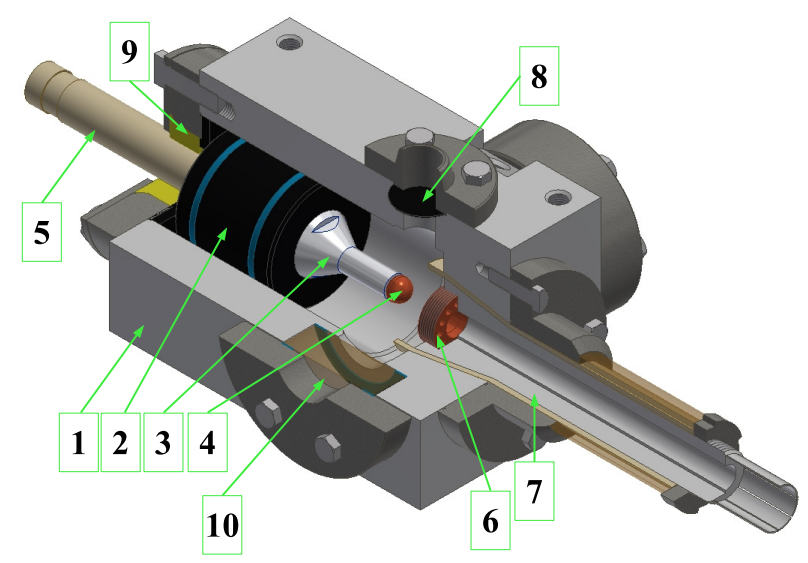

Figure 2. Axial blast discharge chamber: (1) housing; (2) piston; (3) anode holder; (4), (6) contacts; (5) polycarbonate tube; (7) current input; (8) diaphragm; (9) fluoroplastic cartridge; (10) diagnostic window.

Copper and $\mathrm{MoWCu}$ were used as materials for ring contact. And copper, $\mathrm{CuFe}$ and $\mathrm{CuW}$ for rod contact.

During the initial moment the rod contact enters into a cavity of current input on depth of $4 \mathrm{~cm}$ inside ring contact. Movement of the piston is carried out by means of compressed gas. Gas leaves from the discharge chamber into receiver volume after break of a diaphragm (8). The cavity behind the piston plays a role of the shock-absorber since gas is squeezed out from it through a narrow slit between a tube (5) and the fluoroplastic cartridge (9). Windows (10) are purposed for optical diagnostics.

The photo of the discharge chamber, mounted on the stand, is shown in figure 3.

Functioning of system occurs in the following sequence. The energy source (capacitor battery) is charged up to a necessary voltage. Then working gas with the help of the remote controlled valve enters into the high pressure cylinder through gas pipe line galvanically untied from installation. At the set pressure the polyester diaphragm tear, and gas starts to enter into the discharge volume. Under action of gas pressure the piston (2) begins movement. On the end

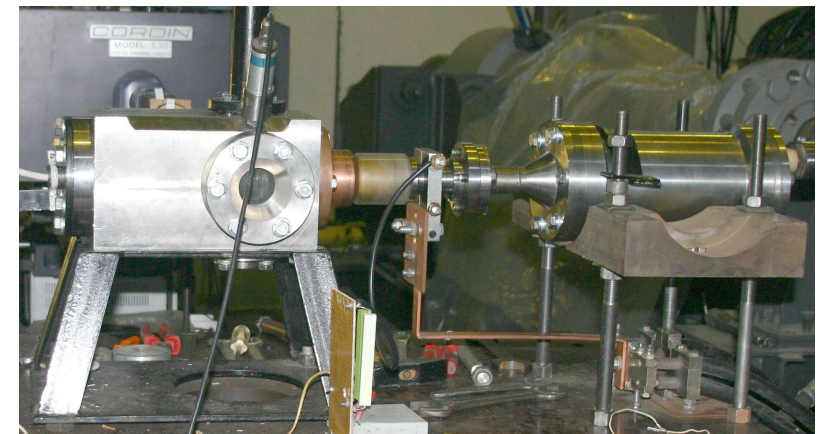

Figure 3. Discharge chamber on the experimental stand.

of the tube (6), made of shock-resistant polycarbonate, the plate with slits is attached. At passage of these slits by the photo diode it lights up, and on pulses from the photo diode the speed of the piston is determined. The end of the plate tears the thin wire tense across its movement, and the forming circuit gives out a signal on the discharge of the capacitor battery and start diagnostic and data-acquisition equipment. Ignition time for switching a current is chosen so that the discharge began before the moment of contacts disconnection. Thus, the discharge current starts at normally closed contacts. After contacts disconnection an electric arc, which length increases in process of the piston movement, ignites between them. Piston speed equal to contact separation speed was of $15-35 \mathrm{~m} / \mathrm{s}$ at the 4 th millisecond.

Filling the discharge chamber with gas before ignition of the arc has been occurred until the limiting diaphragm (8) was broken at a given pressure. Then gas flowed to the receiver tank with decreasing pressure, as shown in figure 4 . When the gas output was bunged (cover plug in place of diaphragm (8)) the chamber volume was filled according to figure 5. Highfrequency fluctuation in experimental curve, probably, is due to the sensor natural frequency. Calculated pressure curves are shown together with the experimental pressure curves in figures 4 and 5 . The pressure was calculated by the code in the computing package OpenFOAM $[20,21]$. The discharge current start occurs at the 4th millisecond for the scale in figures 4 and 5 .

Certain unresolved questions do not allow to show the pressure curve during discharge. Some modifications of the simulation scheme and pressure measurement system are carried out now for verification of the measurement data and comparison with simulation results.

The current and voltage across the discharge gap are shown in figure 6 for power mode with half-period of $\approx 1 \mathrm{~ms}$. During the first $100 \mu \mathrm{s}$ after the current start, a short-circuit current flows between the closed contacts. Rod contact moves along the surfaces of the ring one and this leads to intermittent contact bounce and, as a consequence, to voltage spikes. Further, the arc burns in a narrow gap between rod and ring contacts with declining voltage. After that, the rod 


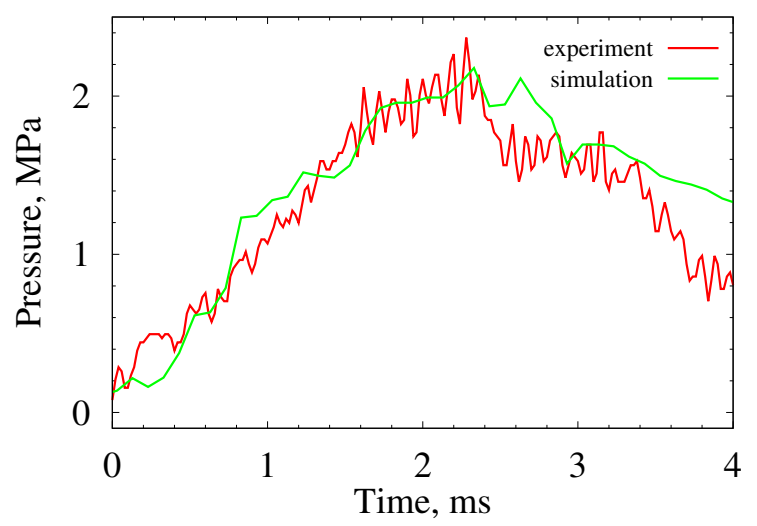

Figure 4. Experimental (red) and calculated (green) pressure in the discharge chamber with diaphragm breaking at $2 \mathrm{MPa}$ for inlet pressure of $4 \mathrm{MPa}$.

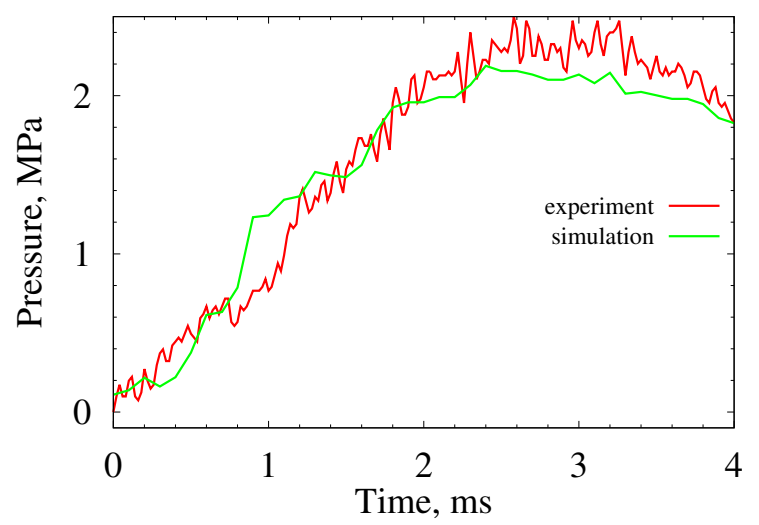

Figure 5. Experimental (red) and calculated (green) pressure in the closed discharge chamber for inlet pressure of $4 M P a$.

contact exited ring contact hole. And this time interval of $4.8-5.3 \mathrm{~ms}$ with intense gas blowing through the arc is specified by considerable increase in discharge voltage value. High speed photo and calculated temperature distribution in discharge chamber for the beginning of this time interval are presented in figures 7(a) and 8(a), respectively. Intensive cooling of the gas flow through the discharge gap leads to arc quenching around current zero (figures $7(\mathrm{~b})$ and 8(b)).

\section{Conclusions}

The experimental setup for simulating and investigating the processes that occur in high-current switching devices has been designed. Preliminary experiments for arcs with variable lengths diagnostics were conducted in the designed axial blast chamber. With the development of experimental techniques, the numerical model has been developed for calculations of various processes in the discharge system. To date, a qualitative agreement has been obtained between experimental data and calculations. Further improvements of the experimental and numerical tools are being made now.

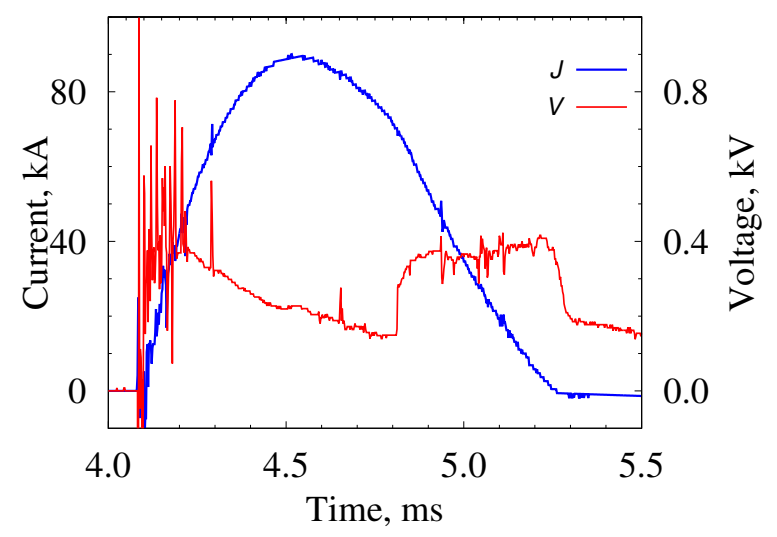

Figure 6. Current (J) and voltage across arc gap (V) in the discharge chamber with diaphragm breaking at $2 M P a$ for inlet pressure of $4 M P a$.
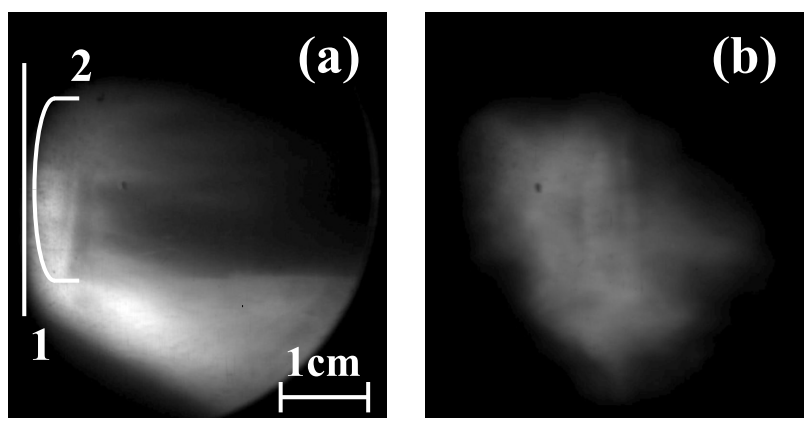

Figure 7. High-speed images of arc between opening contacts at 4.85(a) and 5.4(b) ms with diaphragm breaking at $2 \mathrm{MPa}$ for inlet pressure of $4 \mathrm{MPa}$ : (1) ring contact; (2) rod contact.

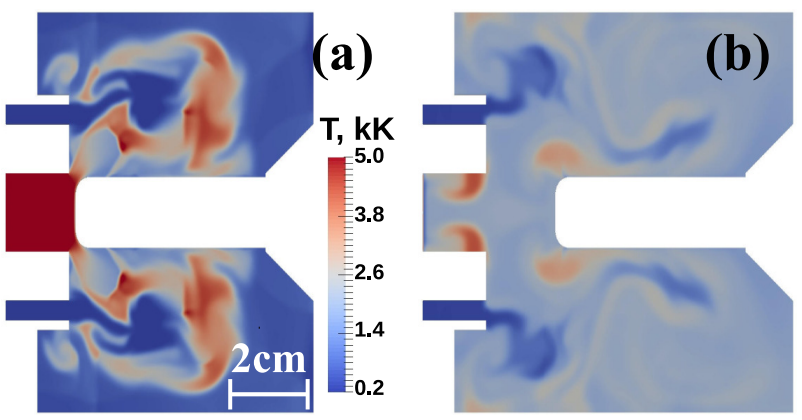

Figure 8. Numerical simulation for temperature distribution in discharge chamber with diaphragm breaking at $2 \mathrm{MPa}$ for inlet pressure of $4 \mathrm{MPa}$; (a) corresponds to $\approx 4.9$ and (b) to $\approx 5.8 \mathrm{~ms}$.

\section{Acknowledgements}

The authors acknowledge the support from Presidium RAS Program No. 7: "New developments in promising areas of energy, mechanics and robotics". Calculation results were obtained using computational resources of Peter the Great Saint-Petersburg Polytechnic University Supercomputing Centre (www.spbstu.ru).

\section{References}

[1] V. Ignatov, M. Misrikhanov, and A. Shuntov. Concerning construction decisions for short circuit 
current limitation in power system. Proceedings of $R A S$. Power Engineering, (5):94-103, 2009.

[2] A. Aleksandrov and V. Zhukov. Restruction of short circuit currents in the high voltage distribution networks of developing power systems. Vestnik MEI, 58(2):58-66, 2012.

[3] Current Zero Club. www. currentzeroclub.org.

[4] P. Glaubitz, S. Stangherlin, J. Biasse, F. Meyer, M. Dallet, M. Pruefert, R. Kurte, T. Saida, K. Uehara, P. Prieur, H. Ito, E. Kynast, A. Janssen, R. Smeets, and D. Dufournet. CIGRE position paper on the application of $\mathrm{SF}_{6}$ in transmission and distribution networks. Electra, 34(274):34-39, 2014.

[5] M. Seeger, R. Smeets, et al. Recent trends in development of high voltage circuit breakers with $\mathrm{SF}_{6}$ alternative gases. Plasma Physics and Technology, 4(1):8-12, 2017. doi:10.14311/ppt.2017.1.8.

[6] M. Eves. A Literature review on $S_{6}$ gas alternatives for use on the distribution network. Western Power Distribution, 2018.

[7] M. E. Pinchuk, A. V. Budin, I. I. Kumkova, and A. N. Chusov. Studying energy evolution in the discharge chamber of a multichamber lightning protection system. Technical Physics Letters, 42(4):395-398, 2016. doi:10.1134/S1063785016040222.

[8] M. Pinchuk, A. Budin, I. Kumkova, A. Bogomaz, A. Sivaev, A. Chusov, and R. Zaynalov. Energy deposition in discharge chamber of lightning protection multichamber system. Journal of Physics: Conference Series, 774(1):012187, 2016. doi:10.1088/1742-6596/774/1/012187.

[9] A. Chusov, E. Rodikova, M. Murmann, H. Nordborg, and R. Fuchs. A review of progress towards simulation of arc quenching in lightning protection devices based on multi chamber systems. Plasma Physics and Technology, 4(3):273-276, 2017. doi:10.14311/ppt.2017.3.273.

[10] P. G. Rutberg, A. A. Safronov, A. V. Surov, A. V. Pavlov, S. D. Popov, V. A. Spodobin, and A. P. Rutberg. Spectral investigations of electric arc alternating current plasma generators with power to 600 kW. High Temperature Material Processes: An International Quarterly of High-Technology Plasma Processes, 13(2):195-203, 2009.

doi:10.1615/HighTempMatProc.v13.i2.80.

[11] A. Surov, S. Popov, V. Popov, D. Subbotin, E. Serba, V. Spodobin, G. Nakonechny, and A. Pavlov. Multi-gas ac plasma torches for gasification of organic substances. Fuel, 203:1007-1014, 2017. doi:10.1016/j.fuel.2017.02.104.
[12] P. Rutberg. Physics and Technology of High Current Discharges in Dense Gas Media and Flows. Nova Science Publishers, 2009.

[13] V. Kolikov, A. Bogomaz, and A. Budin. Powerful Pulsed Plasma Generators: Research and Application. Springer Nature, 2018. doi:10.1007/978-3-319-95249-9.

[14] C. Flurscheim. Power Circuit Breaker Theory and Design. The Institution of Engineering and Technology, 2008. doi:10.1049/PBP0001E.

[15] A. V. Budin, M. E. Pinchuk, V. E. Pilschikov, A. G. Leks, and V. V. Leont'ev. An experimental stand for investigating protective devices for high-voltage overhead lines. Instruments and Experimental Techniques, 59(5):673-677, 2016. doi:10.1134/S0020441216040163.

[16] A. Budin, M. Pinchuk, V. Kuznetsov, V. Leont'ev, and N. Kurakina. Experimental stand for investigations of arc and erosion processes in high-voltage powerful breaker. Instruments and Experimental Techniques, 60(6):837-842, 2017. doi:10.1134/S0020441217060033.

[17] A. V. Budin, M. E. Pinchuk, V. V. Leontev, A. G. Leks, N. K. Kurakina, A. A. Kiselev, J. V. Simakova, and V. Y. Frolov. Experimental stand for investigations of insulator degradation and electrode erosion in high-current breaker. Plasma Physics and Technology, 4(2):120-123, 2017. doi:10.14311/ppt.2017.2.120.

[18] A. V. Budin, M. E. Pinchuk, V. E. Kuznetsov, and F. G. Rutberg. The influence of the production technology of iron-copper composite alloy on its erosion properties in a high-current high-pressure arc. Technical Physics Letters, 40(12):1061-1064, 2014. doi:10.1134/S1063785014120050.

[19] A. V. Budin, M. E. Pinchuk, and N. K. Kurakina. Erosion characteristics of copper-based composite electrodes in an electric arc of variable length with transverse gas blowing. Technical Physics Letters, 44(9):808-810, 2018. doi:10.1134/S1063785018090171.

[20] N. Kurakina, M. Pinchuk, A. Budin, A. Smirnovsky, and V. Frolov. Numerical simulation using OpenFOAM of gas-dynamics in the discharge chamber with a movable electrode. St. Petersburg polytechnic university journal of engineering science and technology, 24(2):69-81, 2018. doi:10.18721/JEST. 240206.

[21] N. Kurakina, M. Pinchuk, A. Budin, and A. Smirnovsky. Analysis of the gas dynamics in the discharge chamber with a movable electrode. Journal of Physics: Conference Series, 1135(1):012094, 2018. doi:10.1088/1742-6596/1135/1/012094. 